\title{
Learning preferences of students studying Physiology in South
} India.

\author{
Navin Rajaratnam ${ }^{1}$, Suganthi V ${ }^{2}$, Suzanne Maria D'cruz ${ }^{3}$ \\ ${ }^{\text {I}}$ (Department of Physiology, Meenakshi Medical College Hospital and Research Institute, Kanchipuram, \\ Tamil Nadu, India.) \\ ${ }_{2}^{2}$ (Department of Physiology, Vinayaka Mission's Kirupananda Variyar Medical College \& Hospital, Salem, \\ Tamil Nadu, India.) \\ ${ }_{3}^{3}$ (Department of Physiology, Sri Muthukumaran Medical College Hospital and Research Institute, Chennai, \\ Tamil Nadu, India.)
}

\begin{abstract}
Teachers of Physiology facilitate the learning of students belonging to different courses and each student has different sensory modality preferences while assimilating information. Students with a visual learning preference prefer learning with graphs and diagrams; students with an auditory preference learn by listening to information; those with a read/write preference prefer textual matter and those with a kinesthetic preference prefer to learn by physical experiences like touching and manipulating material. This study was done to determine the sensory modality learning preferences of first year dental students studying Physiology in South India. The VARK (Visual, Aural, Read/Write, Kinesthetic) questionnaire was administered to 89 first year dental students in a Medical College in South India. Results revealed that the majority of first year dental students (55\%) preferred to use a single sensory modality while learning ie., they had unimodal learning preferences. Out of the students who had a unimodal preference, it was found that $47 \%$ had a preference for the aural modality and $41 \%$ had a preference for the kinesthetic modality. This knowledge of the sensory modality learning preferences of students studying Physiology can act as a catalyst to initiate reflection and subsequent appropriate action by teachers of Physiology.
\end{abstract}

Keywords - Dental students, learning preferences, Physiology, unimodal, VARK

\section{INTRODUCTION}

Teachers of Physiology endeavour to use teaching-learning activities that ensure that the intrinsically complex subject of Physiology is easily understood by diverse groups of students belonging to different courses in their institutions. Knowledge of the diversity of learning styles of their students is one factor that could help these teachers in this process. If the teachers are unaware of the different learning styles of their students, they could sometimes find it challenging to effectively reach all their students in the short time that is allotted for teaching Physiology.

The term 'Learning Style' describes an "individual's preference for understanding his/her experiences and transforming them into knowledge" [1].There are many learning style inventories like Kolb's Learning Style Inventory, Honey and Mumford's Learning Styles Questionnaire, Vermunt's Inventory of Learning Styles and Felder and Soloman's Index of Learning Styles [1,2]. Flemming's VARK (Visual, Aural, Read/Write, Kinesthetic) questionnaire, although widely used, is technically not a learning style questionnaire, according to Flemming himself [3]. It only provides information about the learner's preferred modes of communicating or "modal preference for learning" [4] ie., the sensory modality or modalities they prefer to use while assimilating information. Students with a visual preference prefer learning with graphs and diagrams, while students with an auditory preference learn by listening to information. Students with a read/write preference prefer textual matter while those with a kinesthetic preference prefer to learn by physical experiences like touching and manipulating material.

Many studies using the VARK questionnaire have shown that students of Physiology prefer to use two or more sensory modalities while studying ie., they had multimodal preferences [5-8]. Breckler found that more than half of the pre-medical and pre-dental students were multimodal as were the pre-veterinarian and prepharmacy students [9]. However, a study by Meechan-Andrews found that the majority of students studying Physiology preferred to use only one sensory modality while learning ie., they had a unimodal preference [10] and other researchers who studied the learning preferences of first, second and third year medical and dental students found that only a small minority of students (14.9\% from medical and 30.7\% from dental) preferred multimodal styles [11]. Another study involving first and second year dental students concluded that dental students preferred kinesthetic and aural learning at a higher percentage [12]. No significant differences in sensory modality learning preferences of male and female students of Physiology have been found using the VARK questionnaire $[6,8,9]$. 
Murphy et al. compared the learning preferences of dental students and the 31,243 participants on VARK website and found that while $56 \%$ of the dental students had multimodal preferences, the $44 \%$ who were unimodal preferred visual learning at a higher percentage and kinesthetic learning at a lower percentage than the sample population [13]. They advise that teachers should recognize that their dental students have different learning styles, reflect on their teaching methods and then contemplate incorporating other preferences [13]. A study to determine the factors that affected post-graduate dental students' performance in a Biostatistics course concluded that teachers of dental students should match the learning preferences of as many of their students as possible by using multiple ways of presentation instead of restricting themselves to using only a single method [14]. Felder cautions that while there is no point in tailoring teaching to each student, a teacher who assumes that a "single one-size-fits-all approach" will satisfy the requirements of every student is also wrong [2].

Teachers of Physiology who routinely teach medical students know that strategies that work with students of one course, need not necessarily always work with students of other courses. An awareness of the differences among students and an understanding of the ways students learn are the first few steps among many other steps that are required for ensuring better facilitation of learning. The present study was therefore undertaken to determine the learning preferences of first year dental students studying Physiology in South India. As the purpose of doing our study was only to gather preliminary data to provide information on the sensory modalities used by dental students while assimilating information, and as the VARK instrument is simple, short and easy to understand and score, it was chosen for this study.

\section{AIM}

The aim of the study was to determine the sensory modality learning preferences of first year dental students studying Physiology in South India using the VARK (Visual, Aural, Read/Write, Kinesthetic) questionnaire [3] and to compare the learning preferences of male and female first year dental students.

\section{MATERIALS AND METHODS}

This cross-sectional study involving first year dental students of the 2012-13 batch, was done in the Department of Physiology of Vinayaka Mission's Kirupananda Variyar Medical College \& Hospital (VMKVMCH) in Salem, South India, after obtaining clearance from the Institutional Ethical Committee. The purpose of doing the study was explained and 89 of the 100 first year dental students of the 2012-13 batch, consisting of 22 males and 67 females, gave their written informed consent and participated in the study. The VARK (Visual, Aural, Read/Write, Kinesthetic) questionnaire (C) Copyright held by Neil D. Fleming, Christchurch, New Zealand) consisting of 16 questions [3], was administered to the 89 first year dental students to determine their sensory modality preference while assimilating information. In the VARK questionnaire, there are four possible answers for each of the 16 questions. The students were instructed to choose the answer that best described their preference. They were allowed to choose more than one answer and to leave out a question if they felt that it did not apply to them. Scoring was then done according to the instructions of the VARK questionnaire and the learning preferences of the first year dental students were obtained. SPSS 17 was used for analysis. Z- test for two proportions was used to analyze the difference in learning preferences of male and female dental students.

\section{RESULTS}

The sensory modality learning preferences of 89 first year dental students $(n=89)$, was determined using the VARK (Visual, Aural, Read/Write, Kinesthetic) questionnaire. Analysis of the results revealed that 49 out of the 89 students $(55 \%)$ preferred using a single sensory modality while learning ie., they had unimodal learning preferences, while 40 out of the 89 students (45\%) preferred using two or more sensory modalities ie., they were multimodal.

Out of the 49 dental students who had a unimodal preference, it was found that $47 \%$ had a preference for the aural modality and $41 \%$ had a preference for the kinesthetic modality (TABLE 1 ). Among the 40 multimodal dental students, the largest numbers were VARK (27.5\%) followed by AK and ARK (each with $25 \%$ ), RK (7.5\%), VR and VAK (each with $5 \%$ ) and $2.5 \%$ for AR (TABLE 2).

Gender-wise analysis of the sensory modality learning preferences of the 89 first year dental students consisting of 22 male and 67 female students was done and revealed that there was no significant difference in their sensory modality learning preferences (TABLE 3 ). 
TABLE 1 - Sensory modality learning preferences of Unimodal first year dental students.

\begin{tabular}{|l|l|c|}
\hline \multicolumn{2}{|c|}{ Sensory modality learning preference } & $\begin{array}{c}\text { Number of students and percentage } \\
(\mathbf{n}=\mathbf{4 9 )}\end{array}$ \\
\hline \multirow{4}{*}{ Unimodal } & Visual (V) & $2(4 \%)$ \\
\cline { 2 - 3 } & Aural (A) & $23(47 \%)$ \\
\cline { 2 - 3 } & Read/Write (R) & $4(8 \%)$ \\
\cline { 2 - 3 } & Kinesthetic (K) & $20(41 \%)$ \\
\hline
\end{tabular}

Sensory modality learning preferences expressed as the number of students and the percentage of students (in brackets) who had a preference for each sensory modality, using the VARK questionnaire [3] with $\mathrm{V}=\mathrm{Visual}, \mathrm{A}=\mathrm{Aural}, \mathrm{R}=\mathrm{Read} / \mathrm{Write}$ and $\mathrm{K}=$ Kinesthetic.

TABLE 2 - Sensory modality learning preferences of Multimodal first year dental students.

\begin{tabular}{|c|c|c|c|}
\hline \multicolumn{2}{|c|}{ Sensory modality learning preference } & $\begin{array}{c}\text { Number of students and percentage } \\
(\mathbf{n}=\mathbf{4 0})\end{array}$ \\
\cline { 3 - 4 } & \multirow{3}{*}{ Bimodal } & AK & $10(25 \%)$ \\
\cline { 2 - 4 } & $16(40 \%)$ & RK & $3(7.5 \%)$ \\
\cline { 2 - 4 } & & AR & $1(2.5 \%)$ \\
\cline { 2 - 4 } & VR & $2(5 \%)$ \\
\cline { 2 - 4 } & Tri-modal & ARK & $10(25 \%)$ \\
\cline { 2 - 4 } & $13(32.5 \%)$ & VAK & $2(5 \%)$ \\
\cline { 2 - 4 } & Quad-modal & VRK & $1(2.5 \%)$ \\
& $11(27.5 \%)$ & VARK & $11(27.5 \%)$ \\
\hline
\end{tabular}

Multimodal sensory modality learning preferences expressed as the number of students and the percentage of students (in brackets) having each preference, obtained using the VARK questionnaire [3], with V= Visual, $A=$ Aural, $R=$ Read/Write and $\mathrm{K}=$ Kinesthetic.

TABLE 3 - Comparison of the sensory modality learning preferences of male and female first year dental students.

\begin{tabular}{|c|c|c|c|c|}
\hline $\begin{array}{c}\text { Sensory modality } \\
\text { learning } \\
\text { preference }\end{array}$ & $\begin{array}{c}\text { Males } \\
(\mathbf{n = 2 2})\end{array}$ & $\begin{array}{c}\text { Females } \\
(\mathbf{n = 6 7 )}\end{array}$ & $\mathbf{Z}$ - score & p value \\
\hline $\mathrm{V}$ & $1(4.55)$ & $1(1.49)$ & 0.8383 & 0.40 \\
\hline $\mathrm{A}$ & $6(27.27)$ & $17(25.37)$ & 0.1766 & 0.86 \\
\hline $\mathrm{R}$ & 0 & $4(5.97)$ & -0.1727 & 0.24 \\
\hline $\mathrm{K}$ & $5(22.73)$ & $15(22.38)$ & 0.0331 & 0.98 \\
\hline $\mathrm{AK}$ & $2(9.09)$ & $8(11.94)$ & -0.3672 & 0.71 \\
\hline $\mathrm{RK}$ & $1(4.55)$ & $2(2.99)$ & 0.3519 & 0.73 \\
\hline $\mathrm{AR}$ & $1(4.55)$ & 0 & 1.755 & 0.08 \\
\hline $\mathrm{VR}$ & 0 & $2(2.99)$ & -0.8196 & 0.41 \\
\hline ARK & $4(18.18)$ & $6(8.96)$ & 1.189 & 0.41 \\
\hline VAK & 0 & $2(2.99)$ & -0.8196 & 0.56 \\
\hline VRK & 0 & $1(1.49)$ & -0.5763 & 0.59 \\
\hline VARK & $2(9.09)$ & $9(13.43)$ & -0.5369 & \\
\hline
\end{tabular}

Sensory modality learning preferences of male and female students expressed as the number of male $(\mathrm{n}=22)$ and female $(\mathrm{n}=67)$ students and the percentage of male and female students (in brackets) having each preference, obtained using the VARK questionnaire [3], with V= Visual, $A=$ Aural, $R=$ Read/Write and $K=$ Kinesthetic. $Z$ - score was calculated using Z- test for two proportions, $p$ value of $<0.05$ being taken as significant. 


\section{DISCUSSION}

Our study which was done to determine the sensory modality learning preferences of first year dental students studying Physiology in South India using the VARK (Visual, Aural, Read/Write, Kinesthetic) questionnaire revealed that the majority of first year dental students preferred using a single sensory modality while learning (unimodal learning preference). This finding is contrary to the finding of other researchers who found that students of Physiology preferred to use two or more sensory modalities while internalizing information [5-8] and researchers who specifically addressed the learning preferences of dental students $[9,13]$ and found that they were multimodal. However, our finding is in agreement with the finding of another study by Meechan-Andrews in which students studying Physiology were found to have unimodal preferences [10], and the study on first, second and third year dental students which also found that the majority of dental students had unimodal preferences, while only a minority $(30.7 \%)$ had multimodal learning preferences [11]. What is to be noted however is that the unimodal preference found in our study (55\% unimodal vs $45 \%$ multimodal) is fairly small. Dobson [15] points out that the unimodal preference found in the students of Meechan-Andrews' study was also fairly small (54\% unimodal vs $46 \%$ multimodal).However, teachers of Physiology who teach dental students, the majority of whom have unimodal learning preferences, have to keep in mind that even if the numbers are not large, there theoretically is a chance that they may not reach such unimodal students if they choose a teaching-learning method that excludes their student's single preference.

Our finding that $47 \%$ of the 49 dental students who had a unimodal preference had a preference for the aural modality and $47 \%$ had a preference for the kinesthetic modality is similar to the finding of the study involving first and second year dental students that concluded that dental students preferred kinesthetic and aural learning at a higher percentage [12]. However, our results are not in agreement with the results of the study by Murphy et al. [13], as they found that the majority of their dental students were multimodal (while ours are unimodal) and they found that students with a unimodal preference preferred visual learning at a higher percentage and kinesthetic learning at a lower percentage than the sample population from the VARK website, (while $47 \%$ and $45 \%$ of the students in our study who had a unimodal preference preferred the aural and kinesthetic modality respectively). In our study, only 2 of the 49 students with a unimodal preference preferred visual learning. Based on their study, Murphy et al. concluded that dental students distinguished themselves from other populations by their strong preference for the visual modality and suggested that as they also had a strong read/write preference; lectures with PowerPoint presentations containing many diagrams and pictures would satisfy the needs of most dental students [13]. However, they predicted that first year dental students would require accommodating aural and kinesthetic learning preferences when they enter the second year, as they would encounter pre-clinical dentistry with challenging projects involving manual skills [13]. This observation is encouraging to our students who already have strong aural and kinesthetic preferences and are in that sense ready for the second year. However, our finding about the predominant aural and kinesthetic preferences of the dental students should alert the teachers of Physiology who rely predominantly on PowerPoint presentations with diagrams and written matter in the text. Such material would be preferred only by the minority of their dental students with visual and read/write preferences. Even among the 40 multimodal dental students in our study, the largest numbers after the preference for VARK $(27.5 \%)$ were for AK and ARK (each with $25 \%$ ), again emphasizing the preference for aural and kinesthetic sensory modalities. While it is not right or even practical to attempt to match the teaching style to the learning styles of every student [2], a more balanced strategy catering to the sensory modality preferences of all learners may be adopted by teachers of Physiology to better facilitate the learning of Physiology by their dental students.

There was no significant difference between the proportions of sensory modality learning preferences of male and female dental students. This is in agreement with the findings of other researchers who found that there was no difference in learning styles between male and female students studying Physiology $[6,8,9]$. In our study, 67 of the 89 first year dental students were females. This combined with the small sample size and the use of the VARK questionnaire (and not a learning style questionnaire) could be the limitations of our study. This could limit the usefulness and applicability of results of our study. But as our intention was only to gain preliminary knowledge of the sensory modality preferences of our dental students (which was why we chose the VARK questionnaire), and as learning cannot be measured, we could use these findings as catalysts for our faculty development; reflect on how we teach different groups of students and then take appropriate action; being aware that these are only our students' preferences and not necessarily their strengths [3,4]. We also need to consider that educational researchers favor 'constructive friction' between teaching and learning [16] and deliberate mismatching of learning styles with the intention of challenging learners to grow in preferences they are not comfortable with, while sometimes catering to their learning preferences [2]. 


\section{CONCLUSION}

Our study done to determine the sensory modality learning preferences of first year dental students studying Physiology in South India using the VARK (Visual, Aural, Read/Write, Kinesthetic) questionnaire revealed that the majority of first year dental students preferred using a single sensory modality while learning, preferring the aural and kinesthetic modalities more than the read/write and visual modalities. There was no significant difference in the sensory modality learning preferences of male and female dental students. Knowledge of the sensory modality learning preferences of first year dental students studying Physiology can act as a catalyst to initiate reflection and subsequent appropriate action by teachers of Physiology.

\section{REFERENCES}

[1] Cuthbert PF. The student learning process: Learning styles or learning approaches? Teaching in Higher Education 2005; 10(2): 235-249

[2] Felder RM, Brent R. Understanding Student Differences. J. Engr. Education 2005; 94(1): 57-72

[3] Flemming D. VARK. A Guide to Learning Styles (online) [cited 2013 Jan 5].Available from: http://www.vark- learn.com/english/ page.asp?p_questionnaire

[4] Fleming N, Baume D. Learning Styles Again: VARKing up the right tree! Educational Developments 2006; 7(4):4.

[5] Samarakoon L, Fernando T, Rodrigo C, Rajapakse S. Learning styles and approaches to learning among medical undergraduates and postgraduates. BMC medical education 2013; 13(1): 42.

[6] Slater JA, Lujan HL, DiCarlo SE. Does gender influence learning style preferences of first-year medical students? Adv Physiol Educ. 2007; 31: 336-342

[7] Lujan HL, DiCarlo SE. First-year medical students prefer multiple learning styles. Adv Physiol Educ. 2006; 30 : 13-16

[8] Baykan Z, Naçar M .Learning styles of first-year medical students attending Erciyes University in Kayseri, Turkey. Adv Physiol Educ. 2007; 31(2): 158-160.

[9] Breckler J, Joun D, Ngo H. Learning styles of physiology students interested in the health professions. Adv Physiol Educ. 2009; 33(1): 30-36.

[10] Meechan-Andrews TA. Teaching mode efficiency and learning preferences of first year nursing students. Nurse Educ Today 2009; 29: $24-32$

[11] Haq SM, Yasmeen S, Ali S, Gallam FI. Students' learning styles require modified teaching strategies. Journal of Rawalpindi Medical College 2012;16(2):191-193

[12] Siddiqi KM,Qazi HS,Kurram MS,Farooq U.Learning preferences of dental students at Islamabad Medical and dental College. Pakistan Oral and Dental journal 2012;32(2);326-329

[13] Murphy RJ, Gray SA, Straja SR, Bogert MC. Student learning preferences and teaching implications. J Dent Educ. 2004;68(8):85966.

[14] El Tantawi MM. Factors affecting postgraduate dental students' performance in a biostatistics and research design course. $J$ Dent Educ. 2009;73(5):614-623.

[15] Dobson JL. Learning styles preferences and course performance in an undergraduate physiology class. Adv Physiol Educ. 2009; 33:308-314.

[16] Vermunt JD, Verloop N. Congruence and friction between learning and teaching. Learning and Instruction 1999; 9:257-280 